\title{
Chemical investigations of isotope separation on line target units for carbon and nitrogen beams
}

Cite as: Rev. Sci. Instrum. 77, 03 A708 (2006); https://doi.org/10.1063/1.2171672

Published Online: 24 March 2006

H. Frånberg, M. Ammann, H. W. Gäggeler, and U. Köster

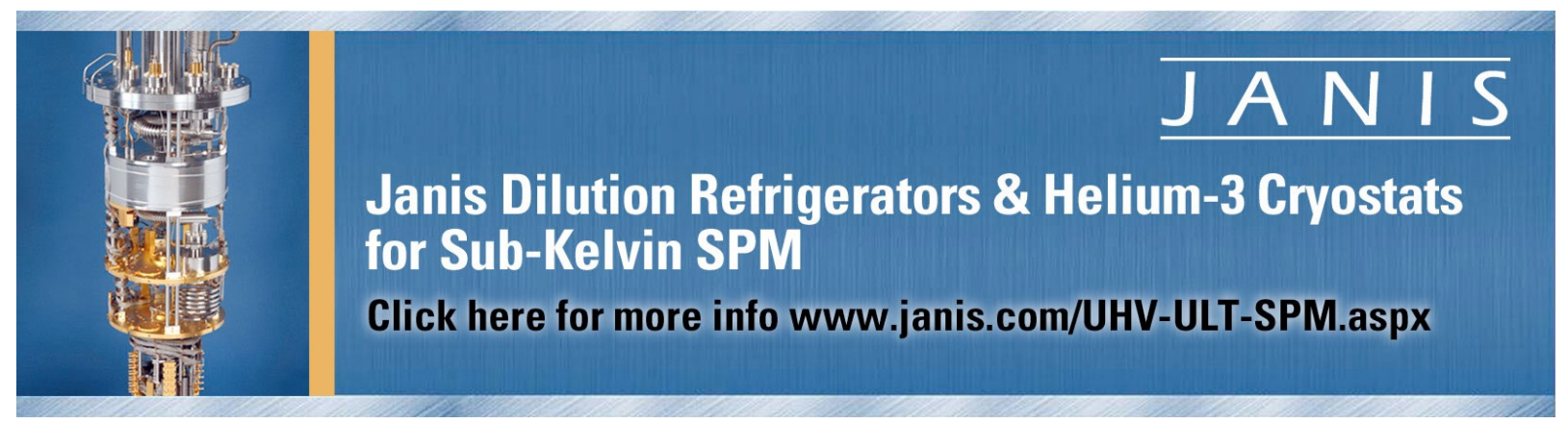




\title{
Chemical investigations of isotope separation on line target units for carbon and nitrogen beams
}

\author{
H. Frånberg \\ ISOLDE, CERN, 1211 Genève 23, Switzerland \\ and Paul Scherrer Institute, 5232 Villigen PSI, Switzerland \\ M. Ammann \\ Paul Scherrer Institute, 5232 Villigen PSI, Switzerland \\ H. W. Gäggeler \\ Paul Scherrer Institute, 5232 Villigen PSI, Switzerland \\ and University of Berne, 3008 Berne, Switzerland \\ U. Köster \\ ISOLDE, CERN, 1211 Genève 23, Switzerland
}

(Presented on 12 September 2005; published online 24 March 2006)

Radioactive ion beams (RIBs) are of significant interest in a number of applications. Isotope separation on line (ISOL) facilities provide RIB with high beam intensities and good beam quality. An atom that is produced within the ISOL target will first diffuse out from the target material. During the effusion towards the transfer line and into the ion source the many contacts with the surrounding surfaces may cause unacceptable delays in the transport and, hence, losses of the shorter-lived isotopes. We performed systematic chemical investigations of adsorption in a temperature and concentration regime relevant for ISOL targets and ion source units, with regard to $\mathrm{CO}_{\mathrm{x}}$ and $\mathrm{NO}_{\mathrm{x}}$ on $\mathrm{Al}_{2} \mathrm{O}_{3}$ and $\mathrm{SiO}_{2}$. These materials are potential construction materials for the above-mentioned areas. Off-line and on-line tests have been performed using a gas thermochromatography setup with radioactive tracers. The experiments were performed at the production of tracers for atmospheric chemistry (PROTRAC) facility at the Paul Scherrer Institute in Villigen, Switzerland. (C) 2006 American Institute of Physics. [DOI: 10.1063/1.2171672]

\section{INTRODUCTION}

At isotope separation on line (ISOL) facilities, typically a hot thick target is bombarded, e.g., with a beam of highenergy (several tens of $\mathrm{MeV}$ up to some $\mathrm{GeV}$ ) protons or heavy ions to produce radioactive isotopes by different nuclear reactions. The target material is placed in a target container in the form of pressed pills, metal foils, liquid metal, or different fiber felt materials. The nuclear reaction products will diffuse through the material and into the surrounding container and then effuse through a transfer line to an ion source. Possible ion sources are surface ionization sources, laser ion sources, or plasma ion sources. Understanding the chemistry in the target and ion source unit is of utmost importance for the optimization of beam intensity and quality since unwanted chemical reactions in the target and ion source unit can lead to important delays in the release process and, hence, losses of short-lived isotopes. The material and temperatures of the transfer line can be varied to achieve optimum conditions for delivering a high-quality beam of the element the users have asked for. For certain elements, in particular, reactive ones, it is advantageous to use chemical evaporation, i.e., molecules instead of atoms for the transport out of the target and into the ion source. In this work, reactions in the target unit of relevance to the production of radioactive ion beams of carbon and nitrogen isotopes have been investigated. Carbon in atomic form is very difficult to evaporate and easily forms even more refrac- tory carbide compounds with hot metal surfaces, e.g., Ta or $\mathrm{W}$, which are typically present in a target and ion source unit. Thus it is of great advantage to consider the release in molecular form as $\mathrm{CO}_{\mathrm{x}}$. $\mathrm{CO}$ and $\mathrm{CO}_{2}$ are produced in an oxygen-rich target environment. Similarly nitrogen is better released in molecular form, e.g., as $\mathrm{NO}_{\mathrm{x}}$, than as atomic radical. In view of the volatility and the relatively low chemical reactivity of these compounds this would allow the minimization of the temperature of the transfer line. Thus, other possibly disturbing radio nuclides can be retained and the beam purity is improved. The effusion time out of the target unit, i.e., the target material, the target container, the transfer line, and the ion source, is dependent on the surface residence time $\left(\tau_{r}\right)$ on all surfaces involved, which is the time that a molecule actually "sticks" to a surface after each encounter. When this time is much longer than the average flight time between two collisions (typically of the order of microseconds), it can contribute significantly to the integral retention time. $\mathrm{Al}_{2} \mathrm{O}_{3}$ and $\mathrm{SiO}_{2}$ are insulating materials that can be used as construction materials or coatings in target and ion source units. They are routinely used in plasma chambers of electron cyclotron resonance (ECR) ion sources, ${ }^{1-3}$ providing a high secondary electron emission as beneficial side effect. ${ }^{4}$

\section{THERMOCHROMATOGRAPHY}

The purpose of thermochromatography (TC) experiments is to investigate the thermodynamics of the reversible 


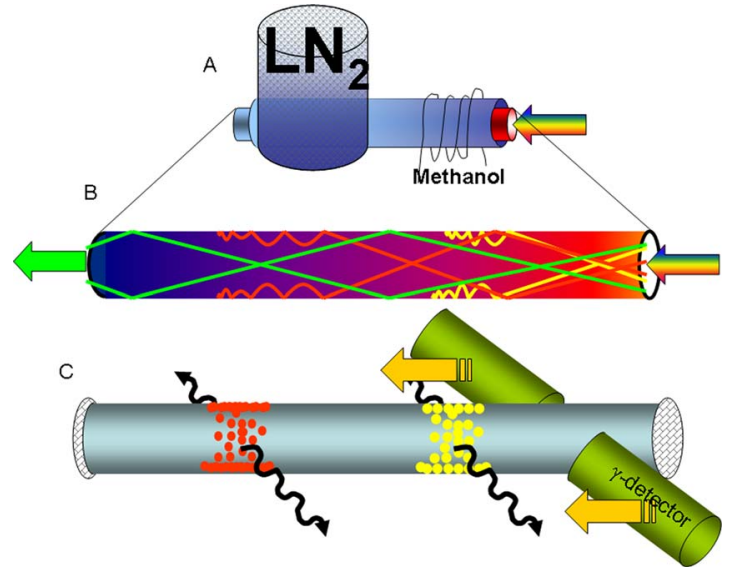

FIG. 1. (Color online) Flow scheme during a TC experiment. (A) The column is positioned within the oven. In our case the "warm" side of the "oven" was cooled with methanol and the cold side cooled with $\mathrm{LN}_{2}$. As shown schematically in (B) the migration of the molecules slows down due to reactions with the wall and comes close to rest at a certain temperature. After the experiment the TC column is sealed and taken out from the TC oven, the column is immersed in a bath of $\mathrm{LN}_{2}$ and scanned repeatedly by two $\gamma$-ray detectors $(\mathrm{C})$.

adsorption or surface reactions of atoms or molecules. In gas $\mathrm{TC}$, a gas containing the isotopes of interest is passing over the material to be investigated under a negative temperature gradient. Atoms or molecules in the gas will adsorb to or react with the surfaces and their migration velocity will diminish due to adsorption (or also chemical reactions) at the walls of the column. Towards the colder end of the TC column this leads to longer and longer residence times on the surface after each collision, until the molecular motion is close to zero. The surface residence times are related to the adsorption enthalpy. Therefore, this method leads to a separation of molecules with different adsorption enthalpies. The adsorption enthalpies can be retrieved from the position (i.e., temperature), where the molecules are detected after a given experimental time.

\section{EXPERIMENTS}

The TC experiments have been performed at the Paul Scherrer Institute, Villigen, Switzerland. The PROTRAC facility $^{5}$ at PSI provided radio-labeled molecular gas, which was used in on-line collections, with a tracer concentration similar to an ISOL target system. The target setup (PROTRAC) is a recently developed system, based on an earlier gas target setup for the continuous on-line production of ${ }^{13} \mathrm{~N},{ }^{6}$ used in atmospheric aerosol chemistry experiments. ${ }^{7,8}$

${ }^{13} \mathrm{~N}$ and ${ }^{11} \mathrm{C}$ are produced in a ${ }^{16} \mathrm{O}$ target bombarded with a $16 \mathrm{MeV}$ proton beam, through the reactions ${ }^{16} \mathrm{O}(p, \alpha){ }^{13} \mathrm{~N}$ and ${ }^{14} \mathrm{~N}(p, \alpha){ }^{11} \mathrm{C}$ (on ${ }^{14} \mathrm{~N}$ contamination of the target gas), respectively. A rapid conversion of the radical molecules formed in the target to $\mathrm{NO}$ and $\mathrm{CO}$ or $\mathrm{CO}_{2}$, respectively, was achieved by passing the gas through a $\mathrm{TiC}$ powder converter at $300-320^{\circ} \mathrm{C}$ immediately downstream of the target. After the conversion the gas was transported through a $590 \mathrm{~m}$ long tube to the laboratory, where it was distributed to up to three parallel experiments. In the present experiments, a constant flow rate of $100 \mathrm{~cm}^{3} / \mathrm{min}$ gas coming from PROTRAC was mixed with $1200 \mathrm{~cm}^{3} / \mathrm{min} \mathrm{N}_{2}$ gas as shown in Fig. 1. All gas

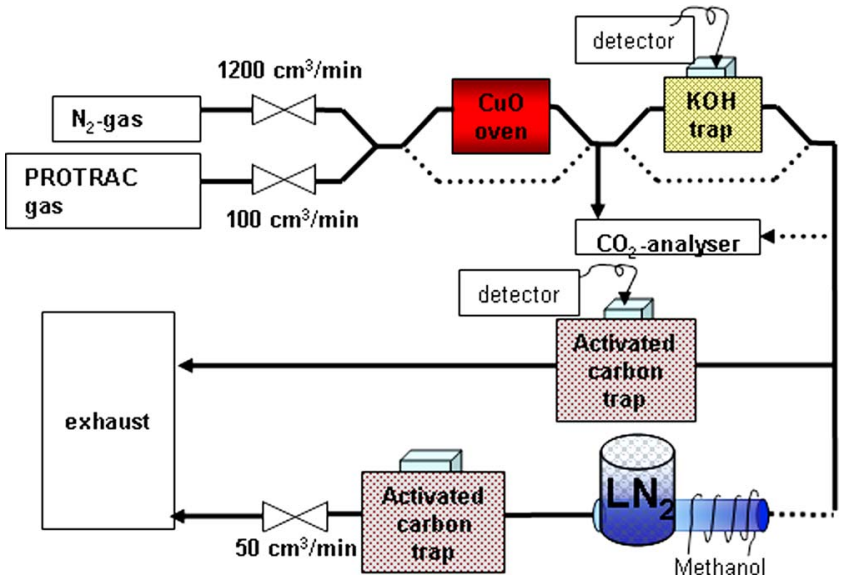

FIG. 2. (Color online) Experimental setup.

transport in the laboratory was through perfluoro-alkoxy copolymer (PFA) tubing held at room temperature. The experiment was performed at atmospheric pressure, and all flows were controlled by mass flow controllers. To measure the concentration of (unlabeled) $\mathrm{CO}_{2}$ in the flow system, a $\mathrm{CO}_{2}$ analyzer was used at different positions along the experimental setup, see Fig. 2. To clearly define the chemical speciation of the ${ }^{11} \mathrm{C}$ isotope used for the following experiments, the gas was passed through a $\mathrm{CuO}$ oven consisting of a quartz tube filled with $\mathrm{CuO}$ splinters kept at $800^{\circ} \mathrm{C}$ for the chemical conversion of $\mathrm{CO}, \mathrm{HCOOH}$ and possibly present hydrocarbons to $\mathrm{CO}_{2}$. A $\mathrm{KOH}$ trap was mounted before the TC column for the absorption of $\mathrm{CO}_{2}$ in characterization experiments (e.g., to determine the amount of labeled and unlabeled $\mathrm{CO}_{2}$ when switching in and out the $\mathrm{CuO}$ oven). Two further chemical traps, filled with activated carbon, were placed parallel to and after the TC experiment, to quantify the amount of all labeled molecules in the gas and the amount of labeled molecules leaving the TC experiment, respectively. For the investigation of $\mathrm{CO}$ and $\mathrm{CO}_{2}$ adsorption on $\mathrm{SiO}_{2}$ and $\mathrm{Al}_{2} \mathrm{O}_{3}$, plain and alumina-coated quartz columns were used. The TC setup consists of a copper tube inside the insulating box; the entrance area is thermostated by methanol held at $233 \mathrm{~K}$ in one experiment and heated to $525 \mathrm{~K}$ in an other experiment, the downstream end where always cooled by liquid $\mathrm{N}_{2}\left(\mathrm{LN}_{2}\right)$. The columns where centered in the $\mathrm{Cu}$ pipe approximately $40-60 \mathrm{~min}$ before each experiment to establish a stable temperature gradient. The temperature gradient used to analyze the samples was measured inside of the collection tube. The gas flow $\left(u_{0}\right)$ was held constant at $50 \mathrm{~cm}^{3} / \mathrm{min}$ by means of a flow controller connected to a pump directly after the column. The collection time was always $40 \mathrm{~min}$. After the collection, both ends of the TC column were sealed and the column quickly retrieved from the TC oven and immersed into a liquid-nitrogen bath, to prevent the migration of eventually desorbing molecules. The liquid nitrogen was covering the column during the whole scanning time. The position of the labeled molecules after an experiment was determined by measuring the coincident $511 \mathrm{keV}$ positrons emitted in the decay of the ${ }^{11} \mathrm{C}$ and ${ }^{13} \mathrm{~N}$ labeled molecules. Two BGO $\gamma$-ray detectors mounted face to face were scanning repeatedly along the column. The identification and differentiation between the $\mathrm{CO}_{\mathrm{x}}$ and $\mathrm{NO}_{\mathrm{x}}$ 

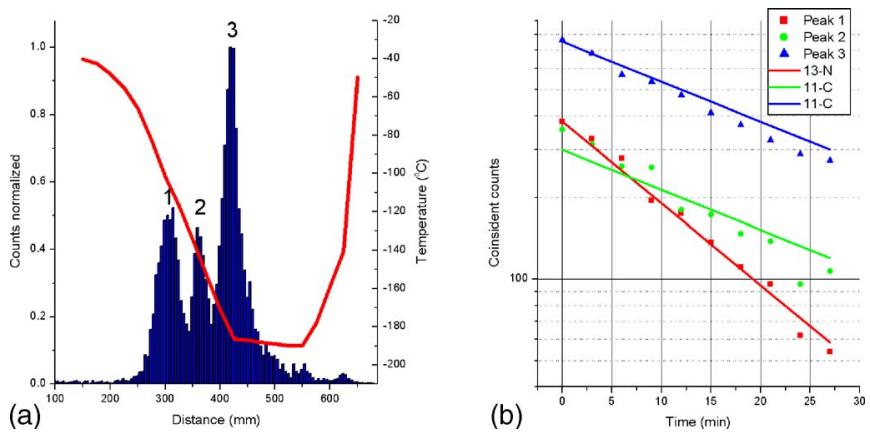

(b)

FIG. 3. (Color online) TC data from a run where the gas passed through a plain quartz tube. On the left (A) the histogram shows the normalized adsorption peaks from the different molecules and the red line gives the temperature profile in the column. The measured individual half-lives of the peaks are shown on the right together with the decay curves of pure ${ }^{11} \mathrm{C}$ or ${ }^{13} \mathrm{~N}$, respectively (B).

molecules were done by means of the different half-lives of ${ }^{11} \mathrm{C}$ and ${ }^{13} \mathrm{~N} \quad\left(T_{1 / 2}=20.38 \mathrm{~min}\right.$ and $T_{1 / 2}=9.96 \mathrm{~min}$, respectively).

\section{RESULTS OF THE EXPERIMENTS}

\section{$\mathrm{NO}_{\mathrm{x}}$ and $\mathrm{CO}_{\mathrm{x}}$ adsorption on $\mathrm{SiO}_{2}$}

Figure 3 shows a histogram of the adsorbed radiolabeled molecules from the PROTRAC gas as they adsorbed at the $\mathrm{SiO}_{2}$ surface. The TC column is kept at temperatures below room temperature to reach retention times which are experimentally accessible (minutes) and thus to deduce the experimental adsorption enthalpies. At higher temperatures no absorption of ${ }^{11} \mathrm{C}$ and ${ }^{13} \mathrm{~N}$ species was observed above background, the absence of any peak at higher temperature means that there is no significant retention in this area during the experiment, the symmetric adsorption peaks are indicating that only reversible adsorption is observed in the lowtemperature experiments and no chemical reaction.

\section{$\mathrm{NO}_{\mathrm{x}}$ and $\mathrm{CO}_{\mathrm{x}}$ adsorption on $\mathrm{Al}_{2} \mathrm{O}_{3}$}

The $\mathrm{Al}_{2} \mathrm{O}_{3}$-coated $\mathrm{SiO}_{2}$ tube provided a higher surfaceto-volume ratio and, thus, the observation of adsorption peaks at higher temperatures. In this experiment the hot end of the TC column was held at $525 \mathrm{~K}$ to study a wider temperature range.

The activity measured in the activated carbon trap after the TC column shows a mixture of ${ }^{11} \mathrm{C}$ and ${ }^{13} \mathrm{~N}$ which means that most of the activity (of both ${ }^{11} \mathrm{C}$ and ${ }^{13} \mathrm{~N}$ ) goes through without significant retention. Analyzing the data also when the $\mathrm{CuO}$ oven and/or $\mathrm{KOH}$ trap are in line with the TC column we can draw the conclusion that the adsorbed peaks come from ${ }^{11} \mathrm{CO}_{2}$, while ${ }^{11} \mathrm{CO}$ had escaped through the column, because the retention of this species was not enough even at the lowest temperatures.

\section{Calculation of the adsorption enthalpy}

From the results shown in Figs. 3 and 4 we can retrieve the deposition temperature associated with each identified molecule. This allows the estimation of adsorption enthalpies
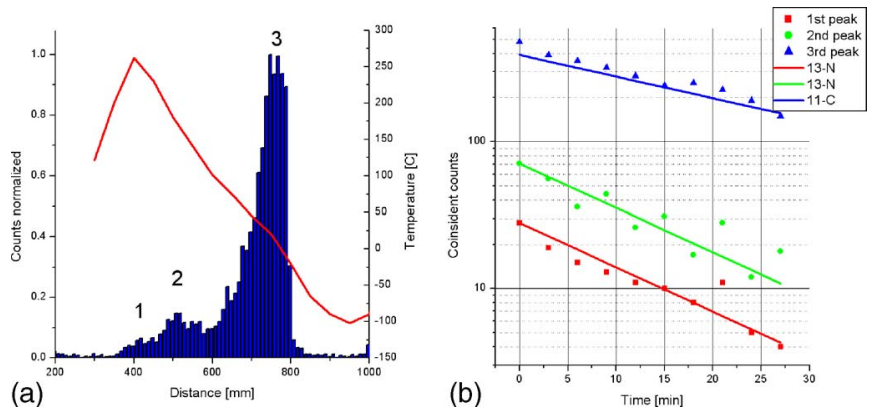

FIG. 4. (Color online) TC data from a run where the gas passed through an $\mathrm{Al}_{2} \mathrm{O}_{3}$ coated quartz tube. The histogram (A) shows the normalized adsorption peaks from the different molecules and the red line shows the temperature in the column. The individual half-lives from the peaks are shown in (B).

with the method described by Eichler and Zvara ${ }^{9}$ using the following two equations, which are based on the laws of classical linear gas chromatography:

$$
\begin{aligned}
& \Delta S=R \ln \left(\frac{A}{V} \frac{1}{\nu_{B}} \sqrt{\frac{k_{B} T_{D}}{2 \pi m}}\right)+\frac{R}{2}, \\
& \left(t+\frac{T_{0}}{g u_{0}} \ln \frac{T_{D}}{T_{S}}\right) \frac{v g u_{0}}{a T_{0}(V / A) e^{\left(\Delta S_{a}^{0} / R\right)}}=\int_{T_{S}}^{T_{D}} \frac{1}{T} e^{-\Delta H_{a} / R T} .
\end{aligned}
$$

An explanation of the input parameters in the equations is given in Table I. Here, we assume that after adsorption on the surface the molecules are left with two translational degrees of freedom. The vibration frequency used in Eq. (1) is calculated from the Lindemann equation, ${ }^{10,11}$

$$
\nu_{B}=2.8 \times 10^{12} \sqrt{\frac{T_{M}}{m V^{2 / 3}}} .
$$

The adsorption enthalpy was calculated through iteratively solving Eq. (2). The adsorption enthalpies obtained are listed in Table II.

\section{DISCUSSION}

Zecchina et al. ${ }^{12}$ gave an estimate of around $21 \mathrm{~kJ} / \mathrm{mol}$ for the chemisorption of $\mathrm{CO}$ on $\mathrm{Al}_{2} \mathrm{O}_{3}$ powder derived from infrared spectroscopy measurements. Their value agrees with the upper limit that we observed. Our result of $\mathrm{CO}_{2}$ on $\mathrm{Al}_{2} \mathrm{O}_{3}$ agrees well with the theoretical study made by Casarin

TABLE I. Notations.

\begin{tabular}{lcc}
\hline \hline Symbol & Explanation & Unit \\
\hline$T_{0}$ & Standard temperature $(293)$ & $\mathrm{K}$ \\
$g$ & Temperature gradient & $\mathrm{K} / \mathrm{m}$ \\
$u_{0}$ & Initial gas flow & $\mathrm{cm}^{3} / \mathrm{min}$ \\
$T_{D}$ & Deposition temperature of the molecule & $\mathrm{K}$ \\
$T_{S}$ & Starting temperature of the experiment & $\mathrm{K}$ \\
$V / A$ & Standard volume to surface area & $\mathrm{cm}$ \\
$\Delta S$ & Adsorption entropy & $\mathrm{J} /(\mathrm{mol} \mathrm{K})$ \\
$\Delta H$ & Adsorption enthalpy & $\mathrm{kJ} / \mathrm{mol}$ \\
$v_{B}$ & Vibration frequency & $s^{-1}$ \\
$k_{B}$ & Boltzmann constant & $1.38066 \cdot 10^{-23} \mathrm{~J} / \mathrm{K}$ \\
$m$ & Molar mass & $\mathrm{kg} / \mathrm{mol}$ \\
$\tau_{R}$ & Retention time & $\mathrm{s}$ \\
\hline \hline
\end{tabular}


TABLE II. The adsorption enthalpies and entropies from our study.

\begin{tabular}{lccccc}
\hline \hline Surface & Molecule & $\begin{array}{c}T_{\text {start }} \\
(\mathrm{K})\end{array}$ & $\begin{array}{c}T_{\text {dep }} \\
(\mathrm{K})\end{array}$ & $\begin{array}{r}\text { Enthalpy } \\
(\mathrm{kJ} / \mathrm{mol})\end{array}$ & $\begin{array}{c}\text { Entropy } \\
(\mathrm{J} / \mathrm{mol} \mathrm{K})\end{array}$ \\
\hline $\mathrm{SiO}_{2}$ & $\mathrm{CO}$ & 112 & $93(10)$ & $-18(1)$ & -153 \\
& $\mathrm{CO}_{2}$ & 148 & $128(10)$ & $-27(1)$ & -153 \\
& $\mathrm{NO}$ & 112 & $93(10)$ & $-18(1)$ & -153 \\
& $\mathrm{NO}_{2}$ & 202 & $163(10)$ & $-34(2)$ & -152 \\
& & & & & -620 \\
$\mathrm{Al}_{2} \mathrm{O}_{3}$ & $\mathrm{CO}$ & & & $-65(3)$ & -162 \\
& $\mathrm{CO}$ & 348 & $293(10)$ & $-100(3)$ & -158 \\
& $\mathrm{NO}$ & 503 & $448(10)$ & $-117(4)$ & -160 \\
\hline \hline
\end{tabular}

et $a l .{ }^{13}(55 \mathrm{~kJ} / \mathrm{mol})$. Pazé et al. ${ }^{14}$ investigated $\mathrm{NO}_{\mathrm{x}}$ desorption from $\delta$ and $\gamma \mathrm{Al}_{2} \mathrm{O}_{3}$ surfaces. They did not quote an enthalpy value for $\mathrm{NO}_{\mathrm{x}}$ on $\mathrm{Al}_{2} \mathrm{O}_{3}$ but their discussion is consistent with our results.

We can now calculate the retention time of $\mathrm{CO}_{\mathrm{x}}$ and $\mathrm{NO}_{\mathrm{x}}$ molecules on a surface of $\mathrm{SiO}_{2}$ or $\mathrm{Al}_{2} \mathrm{O}_{3}$.

$$
\tau_{r}=\tau_{0} e^{-\Delta H / R T},
$$

where $\tau_{0}$ describes the period of oscillation for the molecule adsorbed perpendicular to the surface $\left(\nu_{B}\right)^{-1}$ and $T$ is the temperature of the surface.

The retention times for the materials treated in this report are displayed in Fig. 5 compared to the average time it takes a ${ }^{19} \mathrm{C}^{16} \mathrm{O}$ molecule to fly $1 \mathrm{~cm}$ between two wall interactions. At room temperature the retention times of all studied species on quartz and of $\mathrm{CO}$ on alumina surfaces are negligible. However, for the $\mathrm{CO}_{2}$ and the $\mathrm{NO}_{\mathrm{x}}$ molecules on an $\mathrm{Al}_{2} \mathrm{O}_{3}$ surface the retention times become important below $400{ }^{\circ} \mathrm{C}$. In the example of $\mathrm{CO}_{2}$ on $\mathrm{CaO}$ (a potential target material for the production of radioactive $\mathrm{C}$ and $\mathrm{N}$ isotopes discussed in detail in Ref. 15) the adsorption time at room temperature is extremely long so that for a significant reduction of the retention time for a rapid desorption from this material the temperature has to be kept above ca. $800{ }^{\circ} \mathrm{C}$.

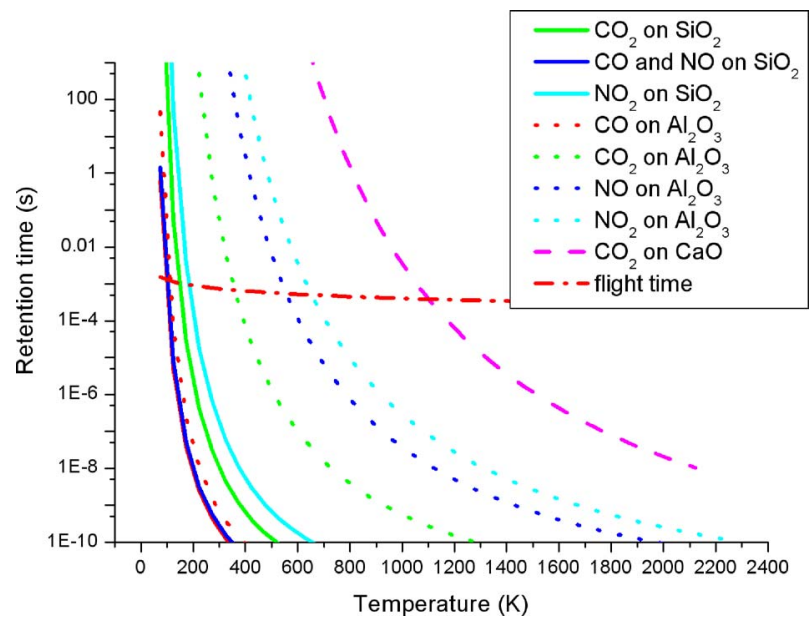

FIG. 5. (Color online) Retention times calculated with the Frenkel equation, Eq. (4), compared with the time it takes for a ${ }^{19} \mathrm{C}{ }^{16} \mathrm{O}$ molecule at thermal speed between two encounters with the wall if the average flight distance is $1 \mathrm{~cm}$.

\section{OUTLOOK}

We have presented the first quantitative measurements of the retention times of $\mathrm{CO}_{\mathrm{x}}$ and $\mathrm{NO}_{\mathrm{x}}$ on quartz and alumina surfaces, materials with widespread use in ion source construction (for $\mathrm{rf}$ windows, insulators, or even the entire plasma chamber). ${ }^{16-18}$ The retention times of $\mathrm{CO}_{\mathrm{x}}$ and $\mathrm{NO}_{\mathrm{x}}$ on quartz are short. Thus, their release time will be comparable to that of noble gases. Plasma ion sources with a quartz chamber which have been successfully used for the production of radioactive ion beams of short-lived noble gas isotopes should perform similarly well for short-lived $\mathrm{C}$ and $\mathrm{N}$ isotopes transported in the form of $\mathrm{CO}_{\mathrm{x}}$ and $\mathrm{NO}_{\mathrm{x}}$. Beams of radioactive $\mathrm{C}$ and $\mathrm{N}$ isotopes have so far been produced at ISOLDE with a forced electron-beam ion arc discharge (FEBIAD)-type plasma ion source. ${ }^{19}$ Strong adsorption losses occur on the hot tantalum surfaces of the target container and the ion source cathode, the hot graphite grid in the ion source, etc. New target and ion source units where most surfaces are covered with quartz or alumina, combined with an efficient 1+ ECR ion source (ECRIS) [e.g., Mono-ECR, ISOLDE (MECRIS) $]^{20}$ promises several orders of magnitude beam intensity gain for short-lived $\mathrm{C}$ and $\mathrm{N}$ isotopes.

So far we only discussed the application for ISOL ion sources $\left(1^{+}\right.$or $\left.n^{+}\right)$which are directly connected to the target, but there are also possible applications to $1^{+} \rightarrow n^{+}$ECRIS charge breeders. ${ }^{21}$ Given the low efficiency for the direct capture of $\mathrm{CO}^{+}$beams in the plasma of an $1^{+} \rightarrow n^{+}$charge breeder ECRIS ${ }^{22}$ a quartz insert into the plasma chamber might help enhance the recycling efficiency of $\mathrm{CO}$ and, hence, lead to a higher overall efficiency for the dissociation and charge breeding of $\mathrm{CO}_{\mathrm{x}}$ and $\mathrm{NO}_{\mathrm{x}}$ beams. ${ }^{23,24}$

\section{ACKNOWLEDGMENT}

This work has been supported by the EU-RTD project TARGISOL (HPRI-CT-2001-50033).

${ }^{1}$ R. Geller, Rev. Sci. Instrum. 69, 1302 (1998).

${ }^{2}$ Z. Xie et al., Rev. Sci. Instrum. 62, 775 (1991).

${ }^{3}$ T. Nakagawa et al., Jpn. J. Appl. Phys., Part 2 32, L1335 (1993).

${ }^{4}$ L. Schächter et al. Rev. Sci. Instrum. 69, 706 (1998).

${ }^{5}$ U. Baltensperger et al., J. Phys. Chem. 97, 12325 (1993).

${ }^{6}$ M. Ammann et al., Radiochim. Acta 89, 831 (2001).

${ }^{7}$ T. Bartels-Rausch et al., Atmos. Chem. Phys. 2, 235 (2002).

${ }^{8}$ A. Vlasenko et al., Aerosol Sci. Technol. 39, 452 (2005).

${ }^{9}$ B. Eichler and I. Zvára, Radiochim. Acta 30, 233 (1982).

${ }^{10}$ K. Mendelssohn, Cryophysics (Interscience, New York, 1960).

${ }^{11}$ G. E. R. Schulze, Metallphysik (Akademie, Berlin, 1974), p. 80.

${ }^{12}$ A. Zecchina et al., J. Catal. 107, 244 (1987).

${ }^{13}$ M. Casarin et al., Inorg. Chem. 42, 436 (2003).

${ }^{14}$ C. Pazé et al., Top. Catal. 30/31, 169 (2004).

${ }^{15} \mathrm{H}$. Frånberg et al. (in preparation).

${ }^{16}$ G. Gimond et al., Nucl. Instrum. Methods Phys. Res. B 70, 118 (1992).

${ }^{17}$ K. Jayamanna et al., Rev. Sci. Instrum. 71, 946 (2000).

${ }^{18}$ K. Jayamanna et al., Rev. Sci. Instrum. 69, 753 (1998).

${ }^{19}$ U. Köster et al., Nucl. Instrum. Methods Phys. Res. B 204, 303 (2003).

${ }^{20}$ F. Wenander et al., Rev. Sci. Instrum. 75, 1627 (2004).

${ }^{21}$ T. Lamy et al., Rev. Sci. Instrum. 73, 717 (2002).

${ }^{22} \mathrm{~T}$. Fritioff et al. (in preparation).

${ }^{23}$ A. G. Drentje, Rev. Sci. Instrum. 74, 2631 (2003).

${ }^{24}$ L. Schächter et al., Rev. Sci. Instrum. 71, 918 (2000). 